\title{
Prediction of Future Trends in Capital Markets using Mining Methodologies
}

\author{
Pooja Taori ${ }^{1}$, Archana Nikose ${ }^{2}$ \\ ${ }^{1}$ M. Tech Semester-III Student, Dept of CSE, RTM Nagpur University, Priyadarshini Bhagwati Chaturvedi College of Engg., Nagpur \\ (M.S), India \\ ${ }^{2}$ Assistant Professor, Department of CSE, Priyadarshini Bhagwati Chaturvedi College of Engg., Nagpur(M.S.), India
}

\begin{abstract}
Which stock should I select? Should I buy today? What will prices be tomorrow, next week or next month? Investing in financial market will be so easy if we know the answers of these questions. A vast amount of research in computer science and technical analysis of stock market had made easy to find out answers of above questions to some extent. This paper attempts to develop an automated approach which combines data mining, a field of computer science and technical analysis, a way of market analysis to help investors grow their money. Prediction of future trends in capital markets is based upon current data and past available data.
\end{abstract}

Keywords: Data Mining, Stock market, Pivot Point Trading, Moving Averages.

\section{Introduction}

Every human being has a common aim of making his/her life easier, comfortable and luxurious. This aim can be fulfilled when he/she have enough money. Capital market is a way through which one can make money by executing trades. The capital market makes it possible to grow small initial sums of money into large ones, and to become wealthy without taking the risk of starting a business or making the sacrifices that often accompany a high paying career.

There are many segments of capital market which includes equity future, equity cash, commodity, agro commodity, forex etc. here in this research we are considering equity future segment for initial implementation. If this implementation is successful then we can take another segment for implementation.

\footnotetext{
About Stock Market

A stock market is a public market for trading of company stocks. Stock market prediction is the act of trying to determine the future price of a company stock or other financial instrument traded on an exchange. The successful prediction of a stock's future price could yield significant profit. The analysis of stock market or in simple terms figuring at what to buy and what to sell and at which price can be done through two methods, fundamental and technical. Fundamental analysis is all about studying and interpreting financial data such as revenues, expenses, assets, liabilities etc. financial statements like balance sheets, cash flow statements, income statement etc. and a financial health of an entity is judged. This analysis is known as quantitative analysis. Technical analysis uses the past traded price and volume data to predict future market price and movement. Technical analysis does not look into the actual nature of market, company, currency or commodity; it is based solely on historical price and volume information. This price data is plotted on chart and analyzed.
}

This paper is an attempt to develop trading strategy using technical indicators such as pivot point, moving averages, support and resistance point.

\section{About Data Mining}

Data mining is the process of analyzing data from different perspectives and summarizing it into useful information information that can be used to increase revenue, cuts costs, or both. Data mining software is one of a number of analytical tools for analyzing data. It allows users to analyze data from many different dimensions or angles, categorize it, and summarize the relationships identified. Technically, data mining is the process of finding correlations or patterns among dozens of fields in large relational databases. For businesses, data mining is used to discover patterns and relationships in the data in order to help make better business decisions. Data mining can help spot sales trends, develop smarter marketing campaigns, and accurately predict customer loyalty. The different steps of the overall methodology that makes use of decision tree for stock prediction are Stock filtering, Data preprocessing, Classification tree and Risk management. Many different techniques of data mining such as neural network, clustering, association rules etc. can be used to predict future stock prices.

\section{Literature Survey}

Ehsan Hajizadeh*, Hamed Davari Ardakani and Jamal Shahrabi [1], presented a work on Application of data mining techniques in stock markets: A survey. This paper provides an overview of application of data mining techniques such as decision tree, neural network, association rules, factor analysis and etc in stock markets. Also, this paper reveals progressive applications in addition to existing gap and less considered area and determines the future works for researchers. 


\section{International Journal of Science and Research (IJSR) \\ ISSN (Online): 2319-7064}

Index Copernicus Value (2013): 6.14 | Impact Factor (2014): 5.611

Mehzabin Shaikh and Gyankamal J. Chhajed [2], describes data mining in the context of financial application from both technical and application perspective by comparing different data mining techniques. They stated, even though different exiting techniques can be used for financial forecasting, but BP neural network will be the best to develop a software tool that can be used for financial forecasting. This work describes the principle of MACD, functions of the signs for aggregation and separation of fast moving average and slow moving average, in addition to double smoothing operation in order to study and determine the timing of buy and sell.

Dr.G.Manoj Someswar, B. Satheesh, G.Vivekanand [3] presented a work on Finance Mining - Analysis of Stock Market Exchange for Foreign Using Classification Techniques. Their proposed analysis reveals progressive applications in addition to existing analysis trading technique using data mining or genetic algorithms for exchange of foreign rates. This work describes the modern finance finding efficient way to summarize and visualize the stock market data to give individuals useful information about the behavior for investment market decision and the data mining classification for stock markets.

Rajesh V. Argiddi, Dr. Mrs. S. S. Apte, Bhagyashri U. Kale [4] Summarized the recent improvements in stock market price prediction from several different perspectives including classic market intelligence techniques, pattern discovery and public web information used for stock data analysis. This paper gives brief overview of several attempts made by researchers for stock prediction by focusing on stock market analysis and defines a new research domain to understand the intelligence of stock market. This refers as stock market intelligence, which is to develop data mining techniques to support all aspects of algorithmic trading and also suggest a number of research issues in stock intelligence related to forecasting \& its accuracy. To do better focus on research, this paper defines the term of Stock market Intelligence to describe all the techniques and methods for stock market analysis \& incorporate to approaches of combining technical indicators, fundamental indicators and expert's opinion, public information to improve stock price prediction using ANN model.

A model CRISP-DM developed by Qasem A. Al-Radaideh, Adel Abu Assaf, Eman Alnagi [5] is used over real historical data of three major companies listed in Amman Stock Exchange(ASE). This model is based on decision tree classifier which is one of the data mining techniques. This model tries to help investors to decide the better timing for buying or selling of stocks based on the knowledge extracted from the historical prices of such stocks. The results for the proposed model were not perfect because many factors including but not limited to political events, general economic conditions, and investors' expectations influence stock market.

Shweta Tiwari, Prof. Rekha Pandit, Prof. Vineet Richhariya [6] presented a work on Predicting future trends in stock market by decision tree rough-set based hybrid system with HHMM . This paper presents a hybrid system based on decision tree rough set, for predicting the trends in the Bombay Stock Exchange (BSESENSEX) with the combination of Hierarchical Hidden Markov Model. In this paper they derives future trends on the bases of price earnings and dividend. The data on accounting earnings when averaged over many years help to predict the present value of future dividends. It is observed by study that the hybrid rough set based system is more accurate then stands alone rough set based system.

\section{Methodology}

The steps through which system will give final conclusion i.e. the trades in which user can work are as follows:

\subsection{Registration of new user/login of existing user}

User has to register himself to use the system. Registration process will demand credentials like name, mobile number, email id, username, and password. By default an email id of a user will be username for that user. Validations are also applied on mobile number and email id for their correctness. After successful registration, user can login through his/her email id (username) and password.
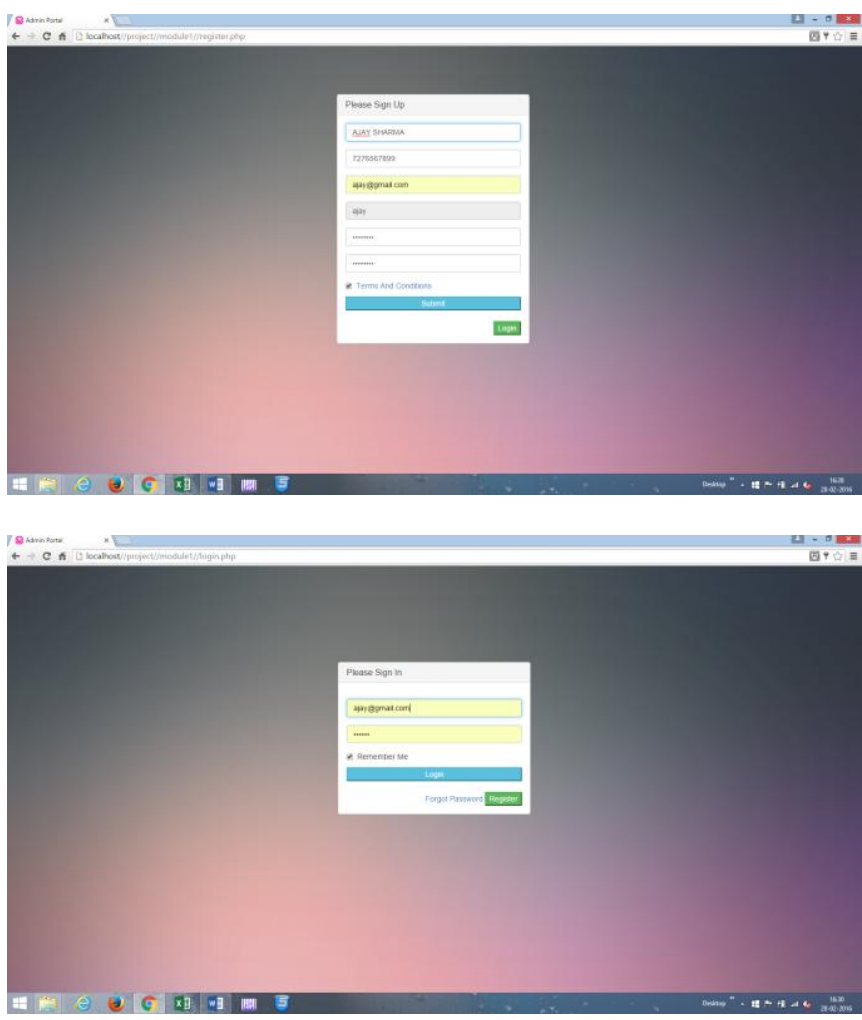

\subsection{Selection of segment, company and duration in which to work}

After successful login user will have to select segment i.e. equity future, equity cash, commodity etc. in which to work. After selecting segment user will have to select company in that segment and the duration in which user has to work. The trading duration of up to two years can be selected. For duration user can either select number of days or date range to work in. The date range is useful when user has to check validity of the system. 


\section{International Journal of Science and Research (IJSR) \\ ISSN (Online): 2319-7064}

Index Copernicus Value (2013): 6.14 | Impact Factor (2014): 5.611

Please select following credentials to proceed

\begin{tabular}{|l|}
\hline Equity Future \\
\hline ACC LIMITED - ACC
\end{tabular}

Suggest Company

SELECT PERIOD

Select Period

- Select Range 01-01-2016-26-02-2016

Process

\subsection{Data loading}

After this selection process past data of selected company for selected duration is loaded in system.

\subsection{Calculations on loaded data}

Pivot formula is applied on loaded data and pivot value is calculated. This pivot value is used for further calculations i.e. calculation of support and resistance values.

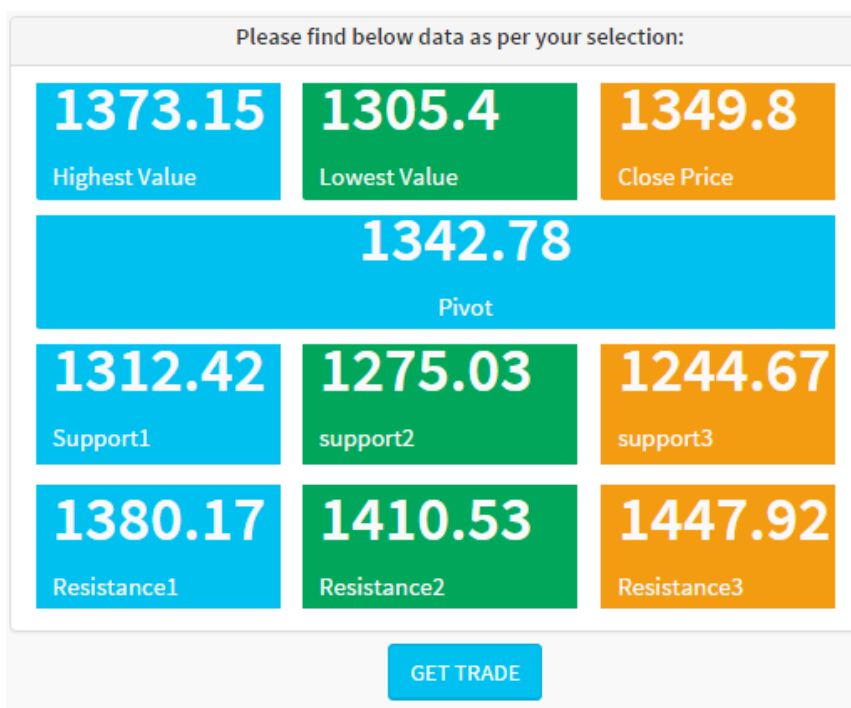

\subsection{Analysis on the calculated values to derive trades}

For one day or one week duration the only required data for analysis is pivot levels but for duration more than one week, the calculations of moving averages along with pivot levels also has to be done. After all this calculations some trading rules are applied on calculated values and trades are derived.

\section{Conclusion}

This paper presents a review of data mining techniques that can be applied on stock market data. Data mining is the process of analyzing and summarizing data from different perspectives and converting it into useful information. Well known data mining techniques that can be used for predicting future trends in capital markets are artificial Neural Network (ANN), decision tree, Bayesian Classifiers etc. Data mining techniques are extensively used in stock market analysis to predict future trends so that investors get more and more profit. Now a days stock market intelligence is one of the widely accepted study in global educational community, there is a need, therefore, to use more and more studies on stock market to get better results and accuracy. Data mining has been applied to a number of financial applications including developing a trading models, investment segment selection, portfolio management, stock selection, duration selection etc. Thus applying data mining techniques on stock market is a need to develop an automated approach which provides investors to take better decision about trading in stock market.

\section{References}

[1] Ehsan Hajizadeh*, Hamed Davari Ardakani and Jamal Shahrabi (2010) "Efficient capital markets: A review of theory and empirical work", Journal of Finance, 25, pp. 383-417.

[2] Mehzabin Shaikh and Gyankamal J. Chhajed (2011). "Forecast Studies for Financial Markets using Technical Analysis". In Proceedings of the International Conference on Control and Automation (ICCA2005), pp. 259-264.

[3] Dr.G.Manoj Someswar, B. Satheesh, G.Vivekanand (2010), "Algorithmic Trading (AT) - Framework for Futuristic Intelligent Human Interaction with Small Investors". International Journal of Computer Applications, vol. 1, no. 21, pp.01-05.

[4] Rajesh V. Argiddi , Dr. Mrs. S. S. Apte, Bhagyashri U. Kale 2009), "Stock market trading rule discovery using two-layer bias decision tree", Expert Systems with Applications, 30, pp.605-611.

[5] Qasem A. Al-R, Adel Abu Assaf Eman Alnagi (2012), "An effective application of decision tree to stock trading", Expert Systems with Applications, 3 pp.270274.

[6] Shweta Tiwari, Prof. Rekha Pandit, Prof. Vineet Richhariya(2012), "A hybrid model for stock market forecasting and portfolio selection based on ARX, grey system and RS theories", Expert Systems with Applications, 36, pp.5387-5392.

[7] Teoh, H. J., Cheng,C-H., Chu, H-H., and Chen, J-S., (2013), "Fuzzy time series model based on probabilistic approach and rough set rule induction for empirical research in stock markets", Data \& Knowledge Engineering, 67, pp.103-117.

[8] Na Jiao. (2011) "Evolutionary Tolerance-Based Gene Selection in Gene Expression Data". J.F. Peters et al. (Eds): Transaction on rough sets XIV, LNCS 6600. Pp 100-118.

[9] Philippe Charlot and Vêlayoudom Marimoutou. (2011) "Hierarchical Hidden Markove Model structure for Dynamic correlations: The Hierarchical RSDC Model". USR 3330 Savoirs et Mondes Indiens.

[10] Binoy.B.Nair, V.P Mohandas, N. R. Sakthivel. (September 2010). "A Decision Tree- Rough Set Hybrid System for Stock Market Trend Prediction". International Journal of Computer Applications (0975 8887). Volume 6- No.9, 
[11] Nikhil Bakshi. (August 2014). "Stock Market Prediction Using Online Data: Fundamental and Technical Approaches Master's Thesis in Computer Science ET". Master's Thesis in Computer Science ETH Zurich.

[12] XindongWu · Vipin Kumar · J. Ross Quinlan · Joydeep Ghosh · Qiang Yang · Hiroshi Motoda · Geoffrey J. McLachlan · Angus Ng · Bing Liu · Philip S. Yu · ZhiHua Zhou · Michael Steinbach · David J. Hand · (2007).Dan Steinberg. "Top 10 algorithms in data mining". (C) Springer- Verlag London Limited

[13] Han, Jiawei and Kamber, Micheline (2006) Data Mining: Concepts and Techniques-Second Edition, Morgan Kaufmann,USA, pp 291-315.

[14] Saad E. W., Prokhorov D.V., and Wunsch, D.C., (1998) "Comparative study of stock trend prediction using time delay, recurrent and probabilistic neural networks", IEEE Transactions on Neural Networks, Vol. 9, No. 6, pp. 1456-1470.

[15] Jacob Vesterlund. (April 2008) A thesis report on "Feature Selection and Classification of cDNA Microarray Samples in ROSETTA".

[16] Luigi Troiano, Pravesh Kriplani. (2010) "Predicting Trend in the Next-Day Marketby Hierarchical Hidden Markov Model". IEEE 2010 International Conference on Computer Information Systems and Industrial Management Applications (CISIM). Pp 199-204.

[17] Mark O. Afolabi, Olatoyosi Olude. (2007) "Predicting Stock Prices Using a Hybrid Kohonen Self Organizing Map (SOM)". 40th Hawaii International Conference on System Sciences. 